\title{
A ANÁLISE DA PSEUDOCONCRETICIDADE DO TRABALHO NA REFORMA DO ESTADO BRASILEIRO NOS ANOS NOVENTA
}

\author{
Gilvan Dias de Lima Filho ${ }^{1}$
}

\section{Resumo}

A laboração do conhecimento é tradicionalmente concepta através da interação entre o sujeito que aprecia (cognoscente) e o objeto que é contemplado (cognoscível). Não obstante de parecer uma ação de reação tão natural ao homem à manifestação dessa vinculação entre o ser e o objeto não se torna obrigatoriamente sinônimo pleno da compreensão humana do real dentro da realidade. Como ratificação dessa limitação reservada, muitas vezes sancionada como fato social, constata-se a atuação cronológica perniciosa do homem contra si mesmo, respaldado em suas manifestações autodestrutivas dentro dos diversos sistemas de produção historicamente vigentes, em particular no capitalismo. Especificamente, a respeito do capitalismo brasileiro contemporâneo este trabalho busca como objetivo central analisar como a Reforma do Estado na década de noventa alterou as condições relacionais do mercado de trabalho. A metodologia emprega foi à dialética materializada na pseudoconcreticidade. Como constatação ratificou-se a intensificação do processo de flexibilização, de desmobilização e de fragilização do trabalho como categoria, compendiada como subtração de ação e ideologia operária, movimento este apoiado por modificações pontuais e graduais da legislação trabalhista que somadas conferem uma dimensão perniciosa e trágica ao futuro da classe trabalhadora e consequentemente ao desenvolvimento nacional.

Palavras-chave: Capitalismo; Reforma do Estado Brasileiro; Trabalho.

\begin{abstract}
The production of knowledge is traditionally defined through the interaction between the subject who appreciates (cognoscenti) and the object which is contemplated (cognoscible). Notwithstanding to seem a response of a reaction so characteristic of the man to the manifestation of this connection between the being and the object does not become necessarily a synonym of human understanding about the real within the reality. As a ratification of this particular limitation that is often considered as a social fact, we can notice that there is a chronological pernicious action of man against himself, who is supported in his self-destructives manifestations within various production systems current historically, in particular, on capitalism. Specifically, regarding the Brazilian contemporary capitalism, this paper seeks as central aim to analyze how the State Reform in the nineties altered the relational skills of labor market. The methodology employed was the dialectic materialized in pseudoconcreticity. As observation, we ratified the intensification of the process of flexibility, demobilization and weakening of labor as a category, which was summed up as subtraction of action and working ideology, a movement supported by specific and gradual modifications of the labor
\end{abstract}

\footnotetext{
${ }^{1}$ Professor Assistente da Universidade Federal de Campina Grande (UFCG). Doutorando em Educação pela Universidade Federal do Ceará (UFC), vinculado à linha de pesquisa Economia, Política, Sociabilidade e Educação. E-mail: gilvandl@ufcg.edu.br.
} 
legislation that when they are added they grant a pernicious and tragic dimension to the future of working class and consequently to the national development.

Keywords: Capitalism, Reform of the Brazilian State, Work.

\section{Introdução}

O modo de produção é o modelo como uma sociedade se constitui para a elaboração, o emprego e a repartição dos bens (usualmente, transformados em mercadorias) gerados continuamente em seus mais diversos setores e sistemas laborativos. Especificamente, o modo de produção de uma sociedade se formaliza pela alocação de suas forças produtivas e nas relações de produção vigorantes nesse coletivo.

Dentre os meios de produção o trabalho é o empenho humano dotado de um intento real e imbuído da transformação da natureza através do dispêndio de competências físicas e mentais. Notadamente, buscando expandir o seu domínio sobre a natureza, o homem historicamente passa a adicionar instrumentos, acrescentando meios artificiais de ação aos meios naturais de seu organismo, ampliando indiscriminadamente a capacidade do trabalho humano de converter a essência do próprio homem. Tornando, a força do trabalho humano à singularidade de ser concomitantemente estirpe de valor para as mercadorias e fragmentação de valor para o homem como ser.

Hodiernamente, no sistema global a situação vigorante do trabalho e do trabalhador acentua-se negativamente, com a eliminação de direitos e a exacerbação de deveres, concomitantemente, com a constituição legalizada de uma nova visão de atuação do Estado reconhecidamente restritiva de seus atributos no âmbito econômico e social, e apoiado na delegação indireta da gestão funcional, "partilhada" com a própria sociedade que passa formalmente a funcionar como "entidades de colaboração" ou "agentes de cooperação" na definição da destinação dos recursos públicos.

Nessa conjunção, o texto busca uma compreensão coeva do trabalho inserido dentro da Reforma do Estado Brasileiro na década de noventa, fundamentado na implementação do diálogo orgânico entre a tradição filosófica clássica alemã (onde está presente a "Categoria Trabalho" de Karl Marx) e a realidade palpável de Karel Kosik (instituída na “Dialética do Concreto”). Designadamente, serão salientadas as mudanças nas condições de trabalho, na determinação dos proventos dos trabalhadores, no uso da força de trabalho e nas leis trabalhistas implementadas a partir, da reformulação do Estado Brasileiro, concebido dentro de uma nova ótica reguladora,

\begin{tabular}{|l|l|l|l|l|} 
Revista Dialectus & Ano 1 & n. 1 & Julho-Dezembro 2012 & p. 109-128 \\
\hline
\end{tabular}


indutora e mobilizadora, cuja função precípua é promover no país (a qualquer custo) uma coordenação estratégica do desenvolvimento, da integração regional e da inserção no mercado internacional.

\section{Dialética do concreto e a pseudoconcreticidade}

Para que seja facultada a compreenção da composição do real fincado dentro de uma realidade, sobretudo, conduzida por interesses classistas hegemônicos, se torna obrigatório transpor a simplificação do mundo das representações caricaturais do ser, da exterioridade dissimulada dos interesses e da apreciação objetiva dos fatos, ou seja, da pseudoconcreticidade que obstrui a autenticidade das ações humanas.

Perceber a essência dos fenômenos torna-se prática não meramente intuitiva, mas sim fundamentalmente analítica, reflexiva, ponderadora, e, sobretudo, subjetiva. Sempre em busca de distinguir o trivial do essencial de cada fenômeno que envolva instâncias particulares ou coletivas, pois, mesmo que o fenômeno apresente-se por inteiro, isto nunca ocorrerá de imediato, sem o uso necessário da conjectura do pesquisador envolvido.

Regularmente, o mundo latente nos apresenta o que perece ser o todo. Doravante o alcance da essência fenomênica se faz mediante sua manifestação. Contudo, a interpretação da manifestação do fenômeno depende da consciência do sujeito que nem sempre é inteiramente cônscio ou neutro para avaliar e julgar criticamente a realidade, extraindo assim as determinações e consequências concretas do cotidiano.

A essência real ou concreticidade permanece oculta no mundo das aparências, desprovendo o homem de sua própria existência. $\mathrm{Na}$ ausência desse como ser, emerge o objeto como produto autônomo de seu criador reduzindo este apenas a práxis utilitária. Práxis aqui entendida como um processo de mudança das circunstâncias, as quais nos possibilitam a formação de ideias, aspirações e pretensões, que, por conseguinte, respectivamente, nos encaminham para a criação efetiva de novos contextos proporcionando a desmistificação de teorias e a conscientização prática dos atos.

Apesar da realidade configura-se com caráter positivista e corpóreo (forma, dimensão, substância), bem como, algo dado, palpável, visível, mensurável, limita-se a uma explicitação primária. No entanto, não se pode contestar que é na realidade que se encontra o real que precisa ser desvelado para provocar a transposição da verdade. Adverte-se que a própria verdade é apenas uma proposição mutável. Proposição 
mutável, pois não existe nem verdade absoluta e nem estancada, em outras palavras, do mesmo modo que o homem se modifica a verdade se transforma, assim, depende de aspectos sociais, econômicos, culturais e políticos em contextos históricos singulares. De acordo com KOSIK (2002)

[...] Compreender o fenômeno é atingir a essência. Sem fenômeno, sem sua manifestação e revelação, a essência seria inatingível. No mundo da pseudoconcreticidade o aspecto fenomênico da coisa, em que a coisa se manifesta e se esconde, é considerado como a essência mesma, e a diferença entre o fenômeno e a essência desaparece. [...]

Por ser efêmera a verdade torna-se cíclica em um processo permanente de construção e ruptura do conhecimento auferido em relação ao fenômeno questionado, tornando indispensável à efetivação de um détour. Assim, impetrar o concreto só se torna plausível através da interposição com o abstrato, pois, a interpretação da essência se faz mediante as particularidades do fenômeno em suas mais diversas feições.

A apreciação e valorização do objeto formalizam-se como valor humano, necessidade de bem-estar, objetivo de vida. Contrapondo-se, a dialética do concreto (como forma de teoria materialista) busca conscientizar a consciência do homem em seu favor, exaltando a este como meio e fim de seu mundo particular e coletivo. Contudo, apesar de parecer algo tão trivial (mostrar ao homem que suas ações devem estar subjugadas a ele e não ao objeto), a conjunção formal estabelecida é de difícil suplantação. Esta totalidade concreta só pode ser conquistada pelo conhecimento da concreticidade do real (do verdadeiro mundo em que o homem se insere).

O sujeito almejado desta plena realidade seria inevitavelmente social. Um ser produtivo, político e mutável. Produtivo por reconhecer que faz parte da essência do homem o trabalho (não necessariamente o trabalho assalariado alienado), como força geradora de conhecimento, riquezas materiais, satisfação pessoal e desenvolvimento econômico. Político por imposição da convivência salutar em sociedade que principia o fato de que nenhum homem dispõe de todas as faculdades humanas desejadas, logo, seria pelo contrato social que eles se completam uns aos outros para assegurarem as decisões e ações de progresso e satisfação (os mais fortes auxiliam os mais fracos; os ricos ajudam os pobres; os sábios ensinam os ignorantes). Mutável por ser livre para eleger entre o que ele considera legitima ou espúrio, por convicções subjetivas ou objetivas. De modo que se o homem é capaz de responder por seus atos, e os seus hábitos decorrem de seus atos, consequentemente o homem é responsável pelos seus hábitos: sejam eles bons ou maus. De forma abreviada, confirma-se nos hábitos o modo

\begin{tabular}{|l|l|l|l|l|} 
Revista Dialectus & Ano 1 & n. 1 & Julho-Dezembro 2012 & p. 109-128 \\
\hline
\end{tabular}


como o homem constrói sua vida através de bônus e ônus retidos ou partilhados no grupo em que coexiste.

Possivelmente, ao observar tudo que se enaltece como relevante ao homem contemporâneo, não é surpresa perceber um coletivo individualista, cético e ganancioso. Tal constatação exalta uma dificuldade ainda maior para transformar um discurso ou teoria em fatos práticos. Modificar um cenário empírico na busca de estabelecer um novo pensamento de autocrítica permanente sobre tudo que faz parte do cotidiano do indivíduo e ainda esperar um entendimento que venha a se transformar em ação pessoal e/ou mobilização coletiva direcionada as mudanças profundas não só em fatos simples mais na própria constituição do sistema de produção vigente, bem como, afrontando segmentos e classes resistentes pelo favorecimento presente é tarefa que principia por alterações e o reconhecimento falsário de conceitos até então admitidos como verdades.

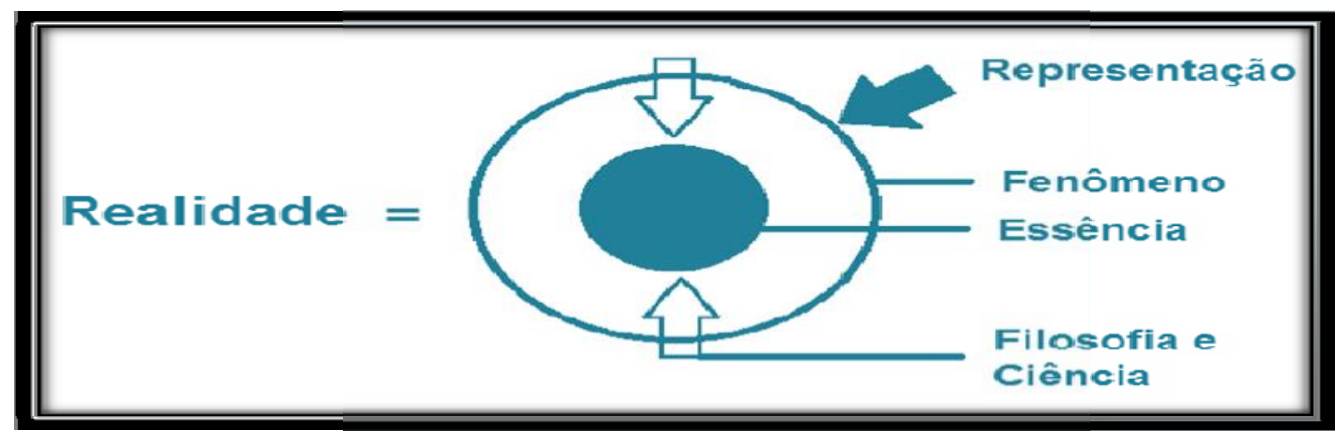

Para Karel Kosik isso decreta uma integração e uma coesão entre a teoria e a prática, ou seja, entre o conhecimento e a ação. Uma percepção de mundo orgânico, gerado pela dialética do concreto em que o "ser" o é em detrimento do "ter" gerando a possibilidade do "vir-a-ser" diferente do "ter" vigorante. Contudo, o "vir-a-ser" não é definitivo, muda de acordo com as necessidades sociais transformando-se assim em uma nova luta entre o "ser" e o "ter" para corresponder as pertinentes alterações. Sobre isso afirma KOSIK (2002)

A realidade é a unidade do fenômeno e da essência. Por isso a essência pode ser tão irreal quanto o fenômeno, e o fenômeno tanto q anto a essência, no caso em que se apresentem isolados e, em tal isolamento, sejam considerados como a única ou "autêntica" realidade.

Não obstante, verifica-se que a realidade pode ser alterada a partir do instante que o homem perceber o seu papel central na concepção social e assim discernir a realidade natural da realidade humano-social, podendo interceder com diferentes 
possibilidades de ação sobre a natureza física (ambiental) e a sua natureza (humana) transformando o mundo e revolucionando o seu modo de viver e conviver. Voltando, assim a "ser" para poder "ter" e não "ter" para poder "ser".

\section{Representação do trabalho no modo de produção capitalista}

O capitalismo apresenta-se como sistema econômico produtivo intencionalmente direcionado a constituição da propriedade e dos meios privados de produção, amparados e assistenciados legalmente por instâncias públicas e voltados para formação, reprodução e acumulação do ganho, norteador da própria essência do capital.

Como organização social materializa-se em contratos de liberdade ou liberdade de contratos, onde as pessoas como sujeito são "livres" para direcionar seus esforços na busca do seu bem-estar. Assim, o capitalismo, segundo seus defensores, seria o modo mais espontâneo e justo de ordenação coletiva, pois, cada indivíduo dependeria exclusivamente da sua própria vontade, empenho e competência para se realizar como ente social. Tudo ocorreria através de permutas voluntárias gerando renda e riqueza como um todo e para todos que assim ambicionassem.

Para Karl Marx o sistema econômico capitalista, nesse sentido, não nos revela a verdadeira lei econômica da sociedade moderna que se fundamenta no processo de trabalho, onde os operários interagem multilateralmente para dispor do uso dos alentos da natureza e, assim, respectivamente, contentar seus desejos e necessidades. Logo, o incremento social estaria inteiramente vinculado com a história do trabalho. $\mathrm{O}$ aprimoramento das ações produtivas proporcionaria à justaposição dos membros da sociedade direcionados a expansão da consciência da utilidade dessa cooperação.

Neste aspecto, o trabalho estende a natureza de ação do homem, proporcionando o desenvolvimento de sua humanidade. Conjunturalmente, esta progressão altruísta ativa do homem quando deformada, desfigura sua relação com a natureza física e pessoal, preenchido pela categoria trabalho alienado que passa a elucubrar a inclusão da transformação, dominação e distorção da realidade. Esse papel negativamente alterado desempenhado pela categoria trabalho alienado reflete o comportamento do homem no capitalista como a história de uma organização produtiva coeva impregnada de injustiça social, que restringi o seu instituidor (o próprio trabalho) em termos de execução e organização social ao utilitarismo mercantilista e a valorização imediata da escassez física conexa como simples gerador da riqueza material (mercadoria e dinheiro). 
Dentro desse envoltório o trabalho é um conceito vasto que deve demandar uma avaliação minuciosa onde se busca demonstrar o foco proposital das relações de poder, com fontes e formas diversas, instituídas e instituintes do próprio trabalho. Para MÉSZÁROS (2002):

O modo capitalista de reprodução social não poderia estar mais distante desta determinação original de produção e propriedade. Sob o comando do capital, o sujeito que trabalha não mais pode considerar as condições de sua produção e reprodução como sua própria propriedade. Elas não mais são pressupostos auto evidentes e socialmente salvaguardados do seu ser, nem os pressupostos naturais do seu eu como construtivos da "extensão externa de seu corpo". Ao contrário, elas agora pertencem a um "ser estranho" reificado que confronta os produtores com suas próprias demandas e os subjuga aos imperativos materiais de sua própria constituição. Assim, a relação original entre o sujeito e o objeto da atividade produtiva é completamente subvertida, reduzindo o ser humano ao status desumanizado de uma mera "condição material de produção". O "ter" domina o "ser" em todas as esferas da vida. Ao mesmo tempo, o eu real dos sujeitos produtivos é destruído por meio da fragmentação e da degradação do trabalho à medida que eles são subjugados às exigências brutalizantes do processo de trabalho capitalista. Eles são reconhecidos como "sujeitos" legitimamente existentes apenas como consumidores manipulados de mercadorias. Na verdade, eles se tornam tanto mais cinicamente manipulados - como fictícios "consumidores soberanos" - quanto maior a pressão da taxa decrescente de utilização.

Retornando à Marx, a categoria trabalho pode ostentar um novo significado na sua

capacidade de definição da essência do homem como ser e espécie desvelando a verdadeira relação entre homem-natureza. Portanto, torna-se evidente que o seu entendimento é indispensável em qualquer momento e época; todavia é ainda mais relevante compreender o trabalho quando a sociedade em questão caracteriza-se de forma excludente, injusta e discriminatória, sobretudo, com quem mais contribui para a constituição material da sua composição social, o trabalhador.

\section{A ontologia e a concreticidade social do trabalho}

Ontologia é um conceito idealizado para explicar a natureza do ser. Trata do ser enquanto ser, isto é, do ser concebido como tendo uma natureza comum, que é inata a todos e a cada um dos seres particularmente. A ontologia é a teoria do ser em geral, da essência do real explicito em sua concreticidade.

Pensada nessa perspectiva e na expressão maior da condição social humana, o trabalho configura-se como inerência do homem, uma expressão de suas faculdades físicas e mentais. Um processo de atividade original e singular, no qual o homem se desenvolve, torna-se ele próprio; o trabalho não é só um meio para um fim - o produto -

\begin{tabular}{|l|l|l|l|l|} 
Revista Dialectus & Ano 1 & n. 1 & Julho-Dezembro 2012 & p. 109-128 \\
\hline
\end{tabular}


mas um fim em si mesmo, a expressão significativa do fundamento humano, simultaneamente, respondendo aos anseios da vida cultural, estética, lúdica, divisionária e social, para cada momento e espaço de desenvolvimento humano. Segundo MARX (1974):

\begin{abstract}
Deve-se evitar antes de tudo fixar a "sociedade" como outra abstração frente ao indivíduo. O indivíduo é o ser social. A exteriorização da sua vida - ainda que não pareça na forma imediata de uma exteriorização de vida coletiva, cumprida em união e ao mesmo tempo com outros - é, pois, uma exteriorização e confirmação da vida social. A vida individual e a vida genérica do homem não são distintas, por mais que, necessariamente, o modo de existência da vida individual seja um modo mais particular ou mais geral da vida genérica, ou quanto mais a vida genérica seja uma vida individual mais particular ou geral.
\end{abstract}

Contudo, a evolução da sociedade em modos de produção mecanizados (como o capitalismo), confirma a perda do trabalho como direito e dever engendrado em um princípio formativo-educativo. Como princípio formativo o trabalho emana do fato de que todos os seres humanos são naturais, portanto, é indispensável socializar, desde a infância, a noção de que é tarefa de todos os seres humanos o provimento da subsistência, procurando-se conceber desse modo à inexistência de uma geração de indivíduos convictos da exploração de terceiros.

O trabalho como princípio formativo não deve ser compreendido limitadamente como uma técnica didática ou metodológica no processo de aprendizagem, mas, sobretudo, como princípio ético-político. Inserido nesse contexto, o trabalho passa respectivamente a ser um compromisso e um direito.

Como compromisso deve ser justo e obrigatório à participação de todos na elaboração da produção dos bens necessários e conspícuos. Como direito passa a ser fato do ser humano se constituir em um ser da natureza que precisa estabelecer, por parte de sua ação consciente, um metabolismo com o meio natural, transformando parte deste em bens, para a sua produção e reprodução. Logo, MARX (1974) constata que:

[...] o homem — por mais que seja um indivíduo particular, e justamente é sua particularidade que faz dele um indivíduo e um ser social individual efetivo é da mesma medida, a totalidade, a totalidade ideal.

Doravante a história do trabalho humano transita unilateralmente da exclusão do trabalho como aspecto ontológico para sua simples incorporação como mercadoria produtiva (força de trabalho) na sociedade capitalista. Como ensejo disso, CHAGAS (2009) afirma:

No capitalismo, o trabalho não aparecerá mais exclusivamente como trabalho útil-concreto, que visa à satisfação das necessidades humana (M-D-M'), mas, 
substancialmente, como mero gasto de força humana de trabalho, como trabalho abstrato, que tem como função específica, como expresso, a valorização do valor (D-M-D'). Trabalho abstrato não é, para Marx, nem simples generalização [...], nem um constructum subjetivo do espírito [...], mas sim uma abstração que se opera no real, uma abstração objetiva do trabalho no capitalismo, a homogeneidade, a redução, a simplicidade, a equivalência, o comum do trabalho social cristalizado num produto, numa mercadoria, que é trocada por outra, a fim de se obter mais-valia.

Com a inclusão do trabalho como mercadoria pelo modo capitalista de produção este passa também a ser concebido como produto agregado com valor de uso e de troca. Faz-se valor de uso no momento da sua empregabilidade produtiva, dando origem a outras mercadorias. Como valor de troca se concretiza na compensação de sua remuneração relacionada ao seu poder de compra (poder aquisitivo), permeada pelo nexo geral da escassez.

Na lógica improcedente do capitalismo o trabalho teria um duplo caráter, pois, seria simultaneamente, resultado do esforço do homem no sentido fisiológico, e nesse predicado de trabalho humano se assemelharia ao trabalho humano abstrato suscitando no valor da mercadoria e gerando, portanto, valor de troca; bem como, se disporia como empenho físico do homem sob contorno designadamente adequada a um fim, e nessa feição de trabalho humano concreto útil produziria valores de uso.

Nesse conforme, Marx esclarece que o valor de troca é fixado pelo montante de trabalho incorporado na força de trabalho, ou seja, é um elemento quantitativo representante do tempo de trabalho socialmente necessário para elaborar e gerar os meios de subsistência, em certo período histórico. Por sua vez, o valor de uso não é idealizado como uma categoria natural, mas como uma categoria peculiar da economia política. $\mathrm{Na}$ esfera da produção capitalista o valor de uso ostenta consignações sociais singulares, que conformam seu emprego no cerne da produção e da circulação do próprio valor de troca. A relação entre o valor de uso e o valor de troca é uma relação de sujeição. O valor de uso compõe o "sustentáculo material" do valor de troca. O valor instituído no processo produtivo deve converte-se em valor de troca através da sua concretização no mercado. Isso, porém, só se torna viável se o valor gerado estiver congregado em um conjunto de valores de uso que satisfazem a imperativos sociais reais. No caso do sistema capitalista de produção é o agregado dos valores de uso que se enquadram para reinstituir os elementos materiais do capital constante (meios de produção) e do capital variável (meios de subsistência) que foram esgotados na produção anterior. Não obstante, deve consentir a expansão futura da produção, mediante a conversão de uma parte da mais-valia em capital constante adicionado e 
capital variável acrescentado. Isso ratifica que, no modo de produção capitalista, o produto social não é designado às necessidades do homem, mas corresponde aos anseios e aspirações do capital.

Portanto, confirmam-se as mercadorias como dimensões sociais, fruto, de relações produtivas passivas, onde o trabalho humano limita-se a ações físicas e intelectuais operacionais, percebidas puramente como formas de atuação desvinculadas de reflexão ou ponderação de sua real participação. Logo, as interações entre os homens em sua produção social capitalista manifestam-se como valores e coisas, podendo-se incluir em ambas as categoria o próprio homem, pois, como fator produtivo restrito o trabalhador não só produz coisas (mercadorias) como se confirma como tal. Como valor de uso gera valor de troca, permitindo ao capitalista pagar pela força despendida menos do que o equivalente ao tempo de trabalho socialmente necessário para reproduzi-la.

A exploração torna-se assim nada anômalo e irregular, é uma típica decorrência do funcionamento padrão do modelo capitalista de produção, surgindo da subtração entre o valor instituído pela força de trabalho e o valor intrínseco da força de trabalho.

Dessa forma, explicita-se a essência do capital conectada ao que ele é e como ele opera. Em si constitui-se no valor da conglobação do trabalho não pago e sempre redirecionado ao processo de produção (e reprodução) do capital. No seu

funcionamento, atua na expropriação da renda e na acumulação da riqueza gerada socialmente, mas, restrita a segmentos privilegiados (aos donos dos meios de produção).

No patamar ideológico, a reprodução que se estabelece é a de que o trabalhador recebe dividendos equivalentes ao seu esforço (ganha o que é justo), pois, parte do pressuposto de que os capitalistas e os trabalhadores que vendem sua força de trabalho, o fazem em uma situação de igualdade e por livre preferência. Dissimulação ratificada mediante o contrato de trabalho que legaliza uma relação desigual.

Como discernimento desta discussão e voltando-se a mercadoria Karl Marx se permitiu visualizar a descaracterização do produto como fruto do trabalho humano, em outros termos, não se reconhece quem produziu apenas o que foi produzido. O valor da mercadoria está em si mesmo e não transcende a isto. Este acontecimento é definido pelo autor como ofetichismo da mercadoria. A sua decorrência é justificar a presença da maisvalia, do lucro e da reprodução do sistema, enaltecendo para isso a aparência, o objeto e a realidade em detrimento da verdade, do sujeito e do real. Escondendo, assim, o conflito entre existência e essência, entre objetivação e autoafirmação, entre liberdade e necessidade, entre capital e trabalho. 


\section{A reforma do Estado brasileiro na década de noventa}

A Reforma do Estado Brasileiro se constituiu empiricamente em um conjunto de mudanças na organização política e social própria dessa instituição jurídico- burocrática, aplicando para isso, uma redisposição e reavaliação dos atributos de quatro estruturas fundamentais: a estrutura pública, exaltando a diferença entre o que deve ser público e o que é coletivo; a estrutura política, baseado no conceito de governabilidade; a estrutura administrativa, exprimindo a noção de governança; e a estrutura econômica, pautada na estabilidade monetária, na internacionalização da economia e no crescimento financeiro sustentável.

Com relação à reforma da estrutura pública esta passa a principiar-se na definição dos bens e serviços que são públicos ou coletivos, pois, o que é público quando puro pode ser representado nas ações do Estado, como a justiça, a segurança e a defesa nacional. Por sua vez, o que é coletivo deve ficar restrito a atuação privada, como o transporte, a comunicação e as matérias-primas. Contudo, existem serviços que por ter um caráter meritório (positivo) para a sociedade materializa-se numa partilha (público e privado), como energia (o governo produz e o setor privado distribui), infraestrutura (o governo constrói e o setor privado administra), e saúde e educação (onde ambos os segmentos disponibilizam, com graus distintos de qualidade e diversidade).

A mudança na estrutura política, por sua vez, esta focada, principalmente no princípio de governabilidade. Principio este entendido como a capacidade política de governar, ou seja, a relação de legitimidade do Estado e de seu governo, diante à sociedade. Logo, o conceito de governabilidade está muito atrelado à adesão que um governo detém de sua população. Buscando mudar uma situação prosaica dos Estados latino-americanos (insira-se nesse contexto o Brasil), que em vários momentos e em diferentes governos enfrentaram crises políticas, que nada mais eram que conflitos de governabilidade, o processo de definição e escolha de seus governantes passaram a ser feito internamento por partidos e diretamente pelo povo. Não obstante, tal fato não é o principal fator invocativo, mais, a incorporação da própria sociedade no processo decisório, baseado na participação de conselhos, diretórios e associações na fixação de prioridades orçamentárias. No entanto, ressalta-se o antagonismo entre a legitimidade real e o caráter figurativo geral desse artificio político, uma vez que, a participação 
coletiva não representa um verdadeiro avanço democrático já que as metas e objetivos, bem como, a definição dos recursos e as alternativas de suas aplicações já foram previamente estabelecidas no próprio bureau do governo.

A reforma na estrutura administrativa centraliza-se no princípio de governança. Esse relacionada à capacidade de colocar as condições da governabilidade em ação, vincula-se à probabilidade normativa de "bom governo", no sentido da implementação dos modelos de eficácia, eficiência, inovação e confiabilidade, buscando evitar a continuidade de métodos distorcidos, usualmente presentes na esfera governamental: como clientelismo, nepotismo e corrupção. Em resumo a governança é entendida como a capacidade financeira e administrativa para pôr em prática, de forma competente, as deliberações governamentais. Designadamente, na década de noventa, conjeturou-se a relevância da adoção da administração gerencial, em substituição do secular conservantismo burocrático. Destarte, conclui-se que a realização dos objetivos da Reforma do Estado perpassa, impreterivelmente, pela reforma do caráter de administrálo e pelo questionamento do padrão burocrático vigorante até então. Como ação destacase a implementação da Lei de Responsabilidade Fiscal aprovada em 2000 e posta em funcionamento em 2001.

As transformações nas estruturas econômicas surgiram ainda nos anos oitenta com a exacerbação das ideias neoliberais disseminadas e aplicadas a partir no Consenso de Washington, especialmente, como solução dos problemas da dívida externa e da crise monetária interna (inflação) dos países em desenvolvimento (latino-americanos). Almejando sanar tais dificuldades o Estado Brasileiro passou por vigorosa reestruturação no uso de suas políticas, instrumentos e recursos econômicos. Conexo às políticas, passa a serem priorizados os aspectos estabilizadores e alocativos intersetorial (entre setores, no caso público e privado) em detrimento aos distributivos (de renda e riqueza) e alocativos intra-setorial (dentro do mesmo segmento, no caso público). Atrelados aos instrumentos, ganha força a equidade da política fiscal (com a necessidade de superávit primário), a regulação da política cambial (com a obrigação de superávit comercial) e a subordinação da política monetária ao combate inflacionário. Conectados aos recursos, vislumbra-se a determinação de pisos para insumos estratégicos (como o salário mínimo) e a fixação de parâmetros para preços universais (como a taxa de câmbio e a taxa de juro Selic). Salienta-se que no agregado o somatório dessas medidas representou ganhos de planejamento para o governo, mas, com graves custos sociais. 
Assim, pode-se constatar que a Reforma do Estado Brasileiro foi uma Reforma Estrutural que tinha como cerne o curso das transformações arraigadas na discussão acerca da construção de um novo modelo de Estado, com novas diretrizes em torno de funções, deveres e obrigações da esfera pública, notadamente, auto-restritivas em amplitude e intensidade. Segundo Bezerra (2011):

Essa orientação no seu conjunto correspondia às grandes diretrizes das agências multilaterais que, desde a Grande Crise de 1982, alargaram seu espaço de imposição e monitoramento da política econômica e social dos "países devedores". Essas duas direções de medidas, uma voltada para a liberalização e desregulementação, e outra, voltada para a redução ou extinção dos serviços do Estado configuram a primeira geração de reformas ditadas pelas instituições multilaterais.

Em um contexto mais amplo, o conjunto de medidas de políticas públicas praticadas pelo governo brasileiro voltado a totalidade social contemporâneo incorre como uma submissão ao capital internacional com explicita precedência conferida à estabilização macroeconômica. Doravante, não é irrelevante o caminho estabelecido nas mutações de concepção e gestão das políticas sociais que, a despeito dos compassos e peculiaridades despontadas em cada caso, conservam entre si uma ligação central.

Como princípio original atribui-se o "mérito" ao montante dos dispêndios públicos sociais à diminuição dos gastos em investimentos governamentais e na formação da poupança nacional. Por já se constituírem em elevados valores absolutos e relativos do $\mathrm{PIB}$, as despesas sociais provocaram, ao longo do tempo, a intensificação e ininterrupta retração do ritmo de crescimento nacional. Como alusão uma segunda disposição centrou-se no refinamento dos instrumentos de descentralização e focalização dos programas sociais. A descentralização foi almejada não apenas para redirecionar parte dos comprometimentos federais às instâncias estaduais e municipais, bem como, para impulsionar a inclusão de outras frações da sociedade civil instituída (sindicatos, fundações, ONG's) na aplicação, no gerenciamento, na fiscalização e no julgamento das ações sociais. Já a focalização foi direcionada as ações e recursos sobre os grupos sociais considerados mais desprovidos como forma ordinária de eliminar as decorrências mais explicitas da pobreza. Expandido, com base em discernimentos de minimização do princípio custo/benefícios e do grau de seletividade do público-alvo, a capacidade de eficiência e eficácia da ação pública. Complementando, uma terceira alteração na percepção do Estado versa em deslocar-se da produção de bens e serviços sociais públicos para as atividades de regulação e regulamentação dos distintos setores sociais. Assim, o Estado deixa de ter como desígnio basilar o provimento de bens e

\begin{tabular}{|l|l|l|l|l|} 
Revista Dialectus & Ano 1 & n. 1 & Julho-Dezembro 2012 & p. 109-128 \\
\hline
\end{tabular}


serviços públicos de natureza social e passa a aperfeiçoar a gestão e a autoridade de sua produção transferida como ação aos segmentos privados. Como exemplo, podemos citar a previdência.

\section{Os impactos da reforma do Estado sobre a força de trabalho}

Apesar da exacerbação apresentada pelo governo brasileiro na década de noventa vinculados ao desempenho do mercado de trabalho nacional, sobretudo, na fomentação de empregos formais, o real dentro da realidade divulgada exibe um quadro antagônico. O desemprego conjuntural, decorrente da insuficiência no crescimento econômico, confirma-se como verídico diante da incompatibilidade da demanda por emprego e da oferta de vagas, com supremacia da primeira, proporcionando, um excedente de mão-deobra em quase todo o país. O desemprego estrutural relacionado com a qualidade do trabalhador, que simploriamente significa que o grau de instrução e de capacitação das pessoas desempregadas não está compatível com as exigências do mercado é latente, exaltando a defasagem entre a educação desqualificada e massificada e as requisições exageradas por trabalhadores polivalentes. O desemprego sazonal vinculado com as oscilações anuais de atividades econômicas específicas como os setores turístico e agrícola fortalecem o trabalhador de ocasião mesmo diante da abertura da economia com a criação de mercados externos cronologicamente sucessivos.

De tal modo conflitante se faz perceber no mesmo período as mudanças negativas impostas legalmente pelo governo com relação à força de trabalho envolvendo aspectos como: condições de proteção ao trabalho; deliberação da remuneração; aplicação da força de trabalho; e a atuação sindical e da Justiça do Trabalho. Exalta-se que pela abrangência e diversidades de ações governamentais efetivas o texto mencionará apenas alguns fatos, buscando ratificar o objetivo concreto do Estado brasileiro a respeito do trabalho.

Em atendimento ao amparo do trabalhador os atos governamentais na regulação da negociação coletiva são adversos. Em setembro de 1995 através da portaria $n^{\circ} 865$ foi executado um desalento na fiscalização das condições de trabalho na qual a partir da constatação do não cumprimento da empresa de questões como segurança e ergonomia, a mesma não seria multada apenas autuadas junto ao Ministério Público. Em 1998 através da MP $\mathrm{n}^{\circ} 1.726$ é determinado a possibilidade de interrupção temporária do 
contrato de trabalho de 2 a 5 meses para a capacitação do funcionário que durante esse período deverá envolver-se em cursos ou programas de qualificação profissional e receberá uma bolsa no valor do seguro-desemprego. Em junho de 1999 por meio de uma complementação da mesma medida provisória é fixado à prorrogação por tempo indeterminado para a qualificação do funcionário que desse modo não precisa ser demitido (contudo, também não aufere o salário vigente que na maioria das vezes é mais alto, bem como, não representa um dilatado custo de demissão).

Em apreço a remuneração do trabalhador deve-se destacar no ano 1994 a execução da MP n ${ }^{\circ} 794$ que regulava a Participação nos Lucros e Resultadas (PLR) dos trabalhadores nos respectivos recursos das empresas. Essa participação ocorreria via negociação coletiva e tinha periodicidade mínima de seis meses. Na prática significou uma substituição de conquistas por ganhos, pois, a participação nos lucros das empresas substituiu a obrigação de aumentos e reposições salariais anuais. Em junho de 1995 entrou em vigor a MP $n^{\circ} 1.053$ impossibilitando a indexação de qualquer categoria salarial, bem como, possibilitando a cessação imediata de acordos considerados inflacionários. Em 1997 é instituída a MP nº 1.096 que passa a fixar unilateralmente o salário mínimo como exclusividade obrigatória anual do poder executivo federal sem qualquer dependência da reposição dos preços ou do custo de vida. Em dezembro de 1999 é efetivada a Lei n ${ }^{\circ} 9.876$ que cria o Fator Previdenciário que ratifica a suspensão da proporcionalidade entre o valor da aposentadoria e das pensões e o tempo de serviço.

Em consideração ao uso da força de trabalho pode-se sobressaltar a Lei ${ }^{\circ} 8.949$ de dezembro de 1994 (popularmente denominada lei das cooperativas) que permitiu a inexistência de vinculo empregatício entre as cooperativas e seus membros. Logo, não seria mais obrigatório o registro em carteira profissional, o pagamento de férias, décimo terceiro salário, previdência social ou descanso semanal remunerado. Prosseguindo com a aplicação de uma nova postura, o governo federal brasileiro, em janeiro de 1995 não adere à convenção da Organização Internacional do Trabalho (OIT) que sancionava obrigações para o encerramento dos contratos de trabalho dificultando dispensas injustificadas. Em janeiro de 1998 entra em vigor a Lei $\mathrm{n}^{\circ} 9.601$ possibilitando a contratação de trabalhadores por tempo determinado (24 meses) em funções já existentes. Como parâmetros aplicativos foram estabelecidos que $50 \%$ dos funcionários poderiam ter contratos determinados, para empresas com até 50 empregados; $35 \%$ dos funcionários, para empresas entre 50 e 199 empregados, e 20\% para empresas com mais de 200 empregados. Como exemplo de constatação da execução dos contratos por

\begin{tabular}{|l|l|l|l|l|} 
Revista Dialectus & Ano 1 & n. 1 & Julho-Dezembro 2012 & p. 109-128 \\
\hline
\end{tabular}


tempo determinado, os trabalhadores empregados durante 18 meses teriam diminuídos em $50 \%$ as alíquotas das contribuições sociais destinadas ao Sistema $\mathrm{S}$, salário- educação e financiamento do seguro de incidentes de trabalho. Também seria contraído de $8 \%$ para $2 \%$ a contribuição patronal ao FGTS, além do não pagamento, pelo empregador, da multa de $40 \%$ sobre o saldo do FGTS do trabalhador no momento da rescisão do contrato de trabalho. Por fim, haveria uma redução no preço das horas extraordinárias realizadas sob a vigência de contratos de trabalho por tempo determinado. Em agosto do mesmo ano foi implementada a MP $\mathrm{n}^{\circ} 1.709$ definindo e regulamentando o trabalho por tempo parcial com jornada semanal de 25 horas. Respectivamente, o salário e o restante dos direitos trabalhistas seriam equivalentes ao número de horas trabalhadas (por exemplo, se o funcionário trabalha-se 25 horas semanais seu salário seria correspondente a $60 \%$ do salário integral e suas férias de 22 dias). Por fim, em dezembro de 1997 entra em vigor a MP $\mathrm{n}^{\circ} 1.522$ estabelecendo as condições de demissão do funcionário público quase sempre justificado pelo excesso de despesas e amparado legalmente. Os servidores exonerados deveriam auferir ressarcimento de um mês de pagamento para cada ano de efetivo exercício no serviço público federal e os cargos desocupados seriam automaticamente suprimidos.

Em relação à atuação sindical alguns pontos merecem menção. Em 1996, o Projeto de Lei ${ }^{\circ} 1.802$ impôs aos sindicados o dolo da greve atribuindo punições que variavam de 500 a 1.000 salários mínimos por dia pela respectiva paralização da categoria. No mesmo ano o Decreto $\mathrm{n}^{\circ} 2.066$ restringia o número de licenças concedidas a servidores públicos para o cumprimento de cargos de representação sindical. Em 1997, o Projeto de Lei ${ }^{\circ} 3.033$ desobriga a contribuição sindical, passando esta a depender da aceitação do trabalhador. Em 1998, a Proposta de Emenda Constitucional $n^{\circ} 623$ elimina a representação sindical única, proporcionando, a existência de mais de um sindicado por categoria ou grupo de trabalhadores. Em analogia a Justiça do Trabalho destaca-se em 1998 a implementação da PEC 623 que delimita a atuação da referida justiça aos dissídios de natureza jurídica (excluindo, assim, os dissídios de natureza econômica) e incorpora as subversões sindicais como área de ação da mesma. Em 2000, a Lei n 9.957 define que os dissídios pessoais de valor igual ou inferior a 40 salários mínimos sejam julgados em audiência exclusiva. No mesmo ano passa a vigorar a Lei ${ }^{\circ} 9.958$ permitindo a criação da Comissão de Conciliação Trabalhista por empresas e sindicados. 
No resumo, torna-se plausível a constatação geral que todas estas medidas aplicadas objetivam intenções internacionais de revalorização do capital, imbuídas de condutas efetivas de transformação social, mesmo que negativamente impresumíveis.

\section{Conclusão}

Inequívoco deve sempre ser a captação do real incluso na realidade. Para Karel Kosik, isso deve ser uma busca e principiar-se com a decomposição do todo para em sequência rematar-se em um somatório geral, tornando-se ao mesmo tempo particular e amplo o elemento construtivo do exato conhecimento e proporcionando a fundamentação para uma estrutura explicativa confiável do agir humano.

Karl Marx desdobrou o estudo do real inserido na realidade ao detalhar a apreciação do trabalho arrolado às formações sociais, as relações econômicas e aos aspectos político-ideológicos, dentro de um sistema produtivo determinado (capitalismo). Constituindo, assim, o embasamento para a compreensão do homem a partir de suas especificidades, porém, como momentos de uma totalidade histórica.

Particularmente, a respeito do momento vigente do capitalismo brasileiro correlacionado aos impactos da Reforma do Estado em curso sobre o mercado de trabalho nacional, ressalta-se: a flexibilização das leis norteadoras das relações de trabalho, objetivadas na desoneração dos dispêndios empregatícios, tipificadamente, dos custos alusivos às condições de emprego (contratação, demissão e jornada de trabalho); aos valores de pagamento (singularidades, determinadas em cada contrato e salário); as diretrizes de proteção (ganhos em detrimentos de conquistas e direitos); e a atuação coletiva (sindicalização e a efetivação da Justiça do Trabalho).

Igualmente importante e execrável é salientar o apoio político de diversos sindicalistas classistas ao segmento patronal na implementação de inovações nocivas direcionadas as admissões, exonerações e mobilidade funcional de trabalhadores, principalmente, mediante aplicação de medidas provisórias, portarias e decretos, que são componentes de menor oposição política. Primado como um conjunto de ações graduais e pontuais de mudanças contraproducentes na legislação trabalhista nacional que somente através de uma apreciação geral e de um retrospecto das duas últimas décadas adquire o verdadeiro caráter nefasto e exalta a intensidade e amplitude da reforma em curso nas relações trabalhistas brasileiras. 
Destarte ratifica-se mais uma vez o capital como uma proposição econômica condicionada ao trabalho. Contudo, na prática a anástrofe dos valores expõe o trabalho como configuração de uma atividade de apropriação e expropriação não apenas de matéria, mas, de vidas. Ratificando o arcano exploratório de apreciação do capital.

\section{Referências Bibliográficas}

ANTUNES, Ricardo. Anotações sobre o capitalismo recente e a reestruturação produtiva no Brasil. São Paulo: Expressão Popular, 2004.

Os sentidos do trabalho: ensaio sobre a afirmação e a negação do trabalho. São Paulo: Boitempo, 1999.

ARNONI, M. E. B. Trabalho educativo e mediação dialética: fundamento teóricofilosófico e sua implicação metodológica para a prática. São Paulo: CD-ROM, Seminário Internacional de Educação - teorias e políticas, 2003.

BARROS, R.P.; HENRIQUES, R.; MENDONÇA, R. Desigualdade e pobreza no Brasil: a estabilidade inaceitável. Rio de Janeiro: IPEA, mimeo, 2000.

BATISTA, P. N. O consenso de Washington: a visão neoliberal dos problemas latinoamericanos. Caderno Dívida Externa, $n^{\circ} 6$.

BEHRING, E. R. Brasil em contra-reforma: desestruturação do estado e perda de direitos. São Paulo: Cortez, 2003.

BEZERRA, J. E. B. Princípios da subsidiariedade, corporativismo e educação. Fortaleza: FACED - UFC, 2011 (Tese de Doutorado).

BRAVERMAN, Harry. Trabalho e capital monopolista: a degradação do trabalho no século XX. 3. ed. Rio de Janeiro: Guanabara Koogan, 1987.

BRITTO, M. A. A era das reformas: a política social no governo Fernando Henrique Cardoso. Brasília-DF: IPEA, mimeo, 2000.

CARDOSO, A. M. Sindicatos, trabalhadores e a coqueluche neoliberal: a era Vargas acabou? Rio de Janeiro: Ed. FGV, 1999.

COUTINHO, Maurício Chafin. Marx e a economia política clássica: trabalho e propriedade. Universidade Estadual de Campinas, Instituto de economia, 1999. Texto para discussão $\mathrm{n}^{\circ} 31, \mathrm{UNICAMP} / \mathrm{IE}$.

DRUCKER, Peter. Sociedade pós-capitalista. São Paulo: Pioneira, 1993.

FRIEDMAN, Milton. Capitalismo e liberdade. São Paulo: Nova Cultura, 1985.

\begin{tabular}{|l|l|l|l|l|} 
Revista Dialectus & Ano 1 & n. 1 & Julho-Dezembro 2012 & p. 109-128 \\
\hline
\end{tabular}


GIANNOTTI, J. A. Introdução. In: Porchat, O. Ciência e dialética em Aristóteles. São Paulo: Editora Unesp, 2001.

GUARESCHI, Pedrinho; RAMOS, Roberto. A máquina capitalista. 5. ed. Petrópolis: Vozes, 2000.

JAPIASSÚ, Hilton \& MARCONDES, Danilo. Dicionário básico de filosofia. 5. ed. Rio de Janeiro: Jorge Zahar, 2008.

KATZ, C. O enfoque marxista da mudança tecnológica. In: KATZ, Claudio; COGGIOLA, Osvaldo. Neoliberalismo ou crise do capital? São Paulo: Xamã, 1995.

KOSIK, Karel. Dialética do concreto. 7. ed. Rio de Janeiro: Paz e Terra. Tradução de Célia Neves e Alderico Toríbio. 2002.

MANDEL, E. A crise do capital; os fatos e sua interpretação marxista. São Paulo: Ensaios, 1990.

MARQUES, R. M. A proteção social e o mundo do trabalho. São Paulo: Bienal, 1997.

MARX, Karl. Contribuição à crítica da economia política. 2. ed. São Paulo: Martins Fontes, 1983.

. Manuscritos econômico-filosóficos: e outros textos escolhidos. In: Os pensadores (coleção). São Paulo: Abril Cultural. Tradução José Carlos Bruni. 1974.

O capital: crítica da economia política. Livro primeiro. Tomo I. São

Paulo: Abril Cultural. Tradução Regis Barbosa e Flávio R. Kothe. 1983.

O capital - livro terceiro: o processo global de produção capitalista,

Rio de Janeiro: Civilização Brasileira, 1974.

Trabalho assalariado e capital. In: ENGELS, Friedrich. Introdução à edição de 1891. São Paulo: Acadêmica, 1987.

MARX, Karl \& ENGELS, Friedrich. A ideologia alemã. São Paulo: Oscite. Tradução José Carlos Bruni e Marco Aurélio Nogueira. 1987.

MENEZES, A. M. D. de, et al. Trabalho, educação, estado e a crítica marxista. In: CHAGAS, Eduardo Ferreira. A natureza dúplice do trabalho em Marx: trabalho útil-concreto e trabalho abstrato. Fortaleza: Edições UFC, 2009.

MÉSZÁROS, István. Para além do capital: rumo a uma teoria da transição. 1. ed. Campinas: Editora da Unicamp, 2002.

PANNEKOEK, Anton, A revolução dos trabalhadores. Florianópolis: Barba Ruiva, 2007.

PEREIRA, L. C. B. A reforma do estado nos anos 90: lógica e mecanismo de controle. In: Cadernos do MARE n ${ }^{\circ}$. Brasília, 1997.

\begin{tabular}{|l|l|l|l|l|} 
Revista Dialectus & Ano 1 & n. 1 & Julho-Dezembro 2012 & p. 109-128 \\
\hline
\end{tabular}


POCHMANN, M. Políticas do trabalho e de garantia de renda no capitalismo em mudança: um estudo sobre as experiências da França, da Inglaterra, da Itália e do Brasil desde o segundo pós-guerra aos dias de hoje. São Paulo: LTR, 1995.

VIANA, Nildo. O capitalismo na era da acumulação integral. São Paulo: Ideias e Letras, 2009. 